\title{
Male Sex as a Factor for Larger Size of Nodal Recurrence and More Tumor Burden (Advanced Disease Stage) in Recurrent Well Differentiated Thyroid Cancer
}

\author{
HOSSAM M. FAREED, M.Sc.*; HAITHAM FEKRY, M.D.*; TAREK EL-BARADIE, M.D.*; \\ MAGDY KOTB, M.D.***; INAS EL-ATAR, M.D.** and ISMAEEL A. MORAD, M.D.* \\ The Departments of Surgery*, Biostatistics** and NuclearMedicine***, National Cancer Institute, Cairo
}

\begin{abstract}
Background: Researchers have examined various factors that may affect recurrence and prognosis in Well Differentiated Thyroid Cancer (WDTC) such as age, sex, tumor size, and histological types. Also several studies tried to classify patients into low, medium and high risk in order to tailor adequate surgical and follow-up planes for each patient. The aim of our study was to study the effect of sex difference on nodal status and tumor burden.
\end{abstract}

Aim of Study: To assess effect of sex difference on size of affected lymph nodes in patients with recurrent well differentiated thyroid cancer.

Patients and Methods: Forty patients with recurrent (WDTC) were studied between June 2014 and June 2015 where adequate surgery was done, L.N. status was assessed pathologically and data was taken and statistically analyzed.

Results: Statistically significant different was found between both sex in relation to size of nodal recurrence in patient with recurrent (WDTC), where larger size of nodes were found in males. ( $p$-value 0.034 )

Conclusion: Male sex is an important factor with may affect burden of the disease, and size of nodal recurrence in patients with (WDTC) which may put those patients into higher risk group that needs special management and followup.

Key Words: Males - Size - Lymph nodes-Recurrence - Well differentiated - Thyroid-Cancer.

\section{Introduction}

THERE have been a large number of researches over the past few decades examining various prognostic factors for both recurrent and mortality in patient with WDTC. Factors such as age $>45$, male sex, large tumor size, histological types, advanced stage of the disease, extrathyroidal extension, lymphatic invasion, and presence of distant metas-

Correspondence to: Dr. Hossam M. Fareed, The Department of Surgery, National Cancer Institute tasis, had all been used as indicator of poor outcome [1-6].

Several studies have attempted to classify patient into low, intermediate, and high risk groups based on the presence of these factors. Prognostication was therefore used to identify patients at high risk who require close follow-up, and prompt therapy for any evidence of recurrence [7-14]

Till now there are no clear reports in literature delineating prognostic factors to predict disease outcome in patients who had suffered multiple reoccurrences and treatment failures of WDTC.

Thus the purpose of this investigation was to examine influence of sex difference as an important factor that may affect nodal status and predict outcome among patients with recurrent WDTC.

\section{Patients and Methods}

The study was carried on 40 consecutive patients with neck recurrence of well differentiated thyroid cancer who were refered to national cancer institute between June 2014 and June 2015. Thirty five of them had associated nodal recurrence that had developed after management of their primary disease. 20 patients had Radioactive Iodine (RAI) as part of their management plan while the other 15 didn't receive (RAI).

For all patient with recurrent disease, data was recorded on demographics, investigation done, initial stage of the disease, number and location of recurrence, time till recurrence, and treatment received. Data was statistically, analyzed, and tabled. 
Patients with recurrent disease were identified by evidence of disease in imaging study, or elevated thyroglobulin level post-operatively or during follow-up.

Surgery was done for recurrent disease as indicated. Study included patients who had done hemithyroidectomy and had other lobe, operative bed or nodal recurrence, patients who had done total thyroidectomy and had operative bed or nodal recurrence, and patients who had done thyroidectomy with neck dissection and had nodal or operative bed recurrence. Patients with incomplete or missed data were excluded.

Completion thyroidectomy was done for other lobe recurrence, neck dissection was done for nodal recurrence in patients without previous neck dissection (therapeutic for clinical nodes and prophylactic for high risk patients) and excision of affected group of nodes was done for patients with previous neck dissection. Excision of recurrence was done for resectable operative bed recurrence. Followup of these patients was taken by history and physical examination, laboratory tests (thyroglobin level) and neck imaging (U.S , C.T, MRI).

Histopathology and risk factors were documented. Patterns of recurrence in thyroid cancer, and associated risk factors for each type of recurrence, (age, sex, most common site of recurrence, level of L.N. affection, number of recurrence, recurrence in less than 12 months) were identified. Surgical management of recurrent thyroid cancer patients was described regarding type of surgery, extent of resection, outcome of surgery in the form of completeness of resection, microscopic or macroscopic residual, and recurrence in less than 12 months. Data was statistically analyzed and tabled.

All patient meeting selective criteria of the study were included in a one year starting from $12 / 2014$ to $12 / 2015$. Last patient will be followedup for 12 months.

Data was managed using SPSS Version 20.0 (IL., Chicago). Data was described as mean and standard deviation. (Or median and range as appropriate). Categorical data was expressed as numbers and percentage. Numbers and percentage among groups were compared using Chi-square/ Fisher exact tests.

Means we're compared by $t$-test or ANOVA (parametric or non-parametric as appropriate. Survival was estimated by Kaplan Meier survival analysis, and log rank test. $p$-value is set significant at 0.05 level.

\section{Results}

Forty patients underwent surgery for recurrent Differentiated Thyroid Cancer (DTC), with female constituting 29 patients $(72.5 \%)$ and male 11 patients $(27.5 \%)$ with male to female ratio (1: 2.63). Five patients had no pathologically affected nodes, one male and four females.

Average males age was (45.09y) and average female age was (45.44y), with youngest male age was (14y), and oldest (61y), and youngest in female was (22y) and oldest (67y), with overall (37.5\%) below or equal (40y), and (62,5\%) above (40y).

Papillary classic pathology was found in 19 patients of the 29 female $(65.51 \%)$, with 2 patients with papillary follicular variant $(6.89 \%), 5$ patients with follicular insular variant $(17,24 \%), 1$ with papillary tall cell variant (3.44\%), 1 with follicular hurthle cell variant $(3,44 \%)$, and one with papillary oncocytic variant (3.44\%).

In the 11 male patients, 9 presented with papillary classic variant $(81.81 \%), 1$ with papillary follicular variant $(9.1 \%)$, and one with papillary columned variant $(9.1 \%)$.

In the 25 female patients with affected nodes, median size of nodal recurrence was $1.75 \mathrm{~cm}$. with minimum size reaching $0.8 \mathrm{~cm}$. and maximum size $3 \mathrm{~cm}$., while in the 10 male patients with affected nodes median size of nodal recurrence was $2.85 \mathrm{~cm}$. with the minimum size was $1.5 \mathrm{~cm}$. and the maximum size reached up to $5 \mathrm{~cm}$. ( $p$-value 0.034 ).

In the female patients median size of operative bed recurrence was $2.8 \mathrm{~cm}$. with minimum size was $0.9 \mathrm{~cm}$. and maximum size $14 \mathrm{~cm}$., while in the male patients median size of recurrence was $1.8 \mathrm{~cm}$. with minimum size reached $0.7 \mathrm{~cm}$ and maximum size reached up to $6 \mathrm{~cm}$ ( $p$-value 0.823 ).

In the 25 female patients, median number of positive removed nodes during surgery were 6 nodes with minimum number of removed nodes was zero, and maximum number of removed positive nodes were 13 nodes, while in male patients median number of positive removed nodes were 4 nodes with the minimum number of positive removed nodes was one node and the maximum number of positive removed nodes were 32 nodes ( $p$-value 0,725$)$.

Of the female patients, 17 (58.6\%) suffered from one recurrence only, while the remaining 12 patients $(41.4 \%)$ suffered more than one recurrence. In the 11 male patients, 7 (63.6\%) suffered from 
one recurrence while the other 4 patients $(36.4 \%)$ suffered more than one recurrence.

And finally in the female patients median time till recurrence was 11 months, with minimum time till recurrence was 2 months, and maximum time reached up till 130 months. In the male patients median time till recurrence was 15 months with minimum time till recurrence was 2 months and maximum time was 84 months. ( $p$-value 0,402$)$.

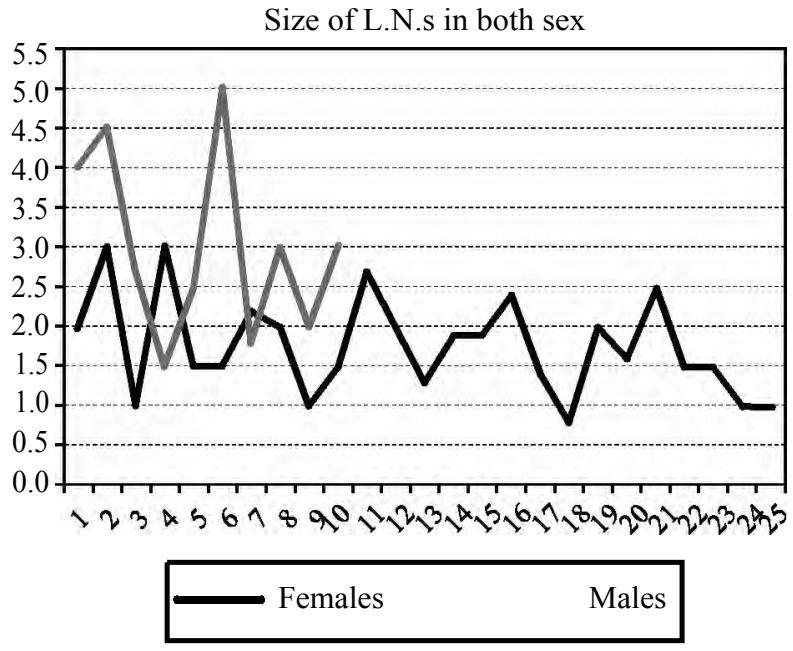

Fig. (1)

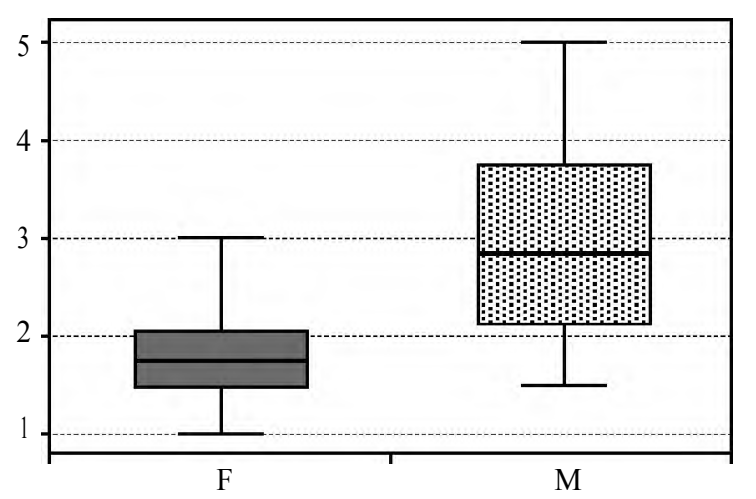

Fig. (2)

\section{Discussion}

Well-differentiated thyroid carcinoma is associated with good disease-specific outcome in the majority of patients. The most important prognostic factors are age and sex [15].

In addition, there are other tumor and treatment factors form the basis of the AMES (age, distant metastasis, tumor ex-tent, and size), AGES (age, tumor size, histologic grade, tumor extent, distant metastasis), and MACIS (distant metastasis, age, completeness of primary tumor resection, local invasion, and tumor size) prognostic scoring systems [16]
This has resulted in the recognition of low-and high-risk patient categories and allowed meaningful comparison of a variety of treatment approaches.

In general, young female patients have the best disease- specific outcome and have allowed a more conservative surgical approach. However, male patients and those older than 45 years have warranted more aggressive combination therapy, which includes total thyroidectomy and adjuvant radioactive iodine [16].

Carsten et al. showed that male sex is one of the most significant independent predictor of developing multiple recurrences in patients with WDTC. He also showed that those patients have a poor prognosis with a significant reduction in tumor free survival [17].

The prognostic importance of sex as an independent factor for development multiple treatment failure despite successful initial salvage therapy is widely recognized $[\mathbf{1 , 3 , 5 ]}$

Machens et al. showed in his study that larger primary tumor size, L.N. metastasis, extrathyroidal extension and distant metastasis were significantly more often with male patients [18].

Nilubol et al. also showed in his study that men had significantly more aggressive histological types, more advanced disease at presentation, larger primary tumor size, higher rates of extrathyroidal extension, L.N metastasis, and distant metastasis [19].

In this study, also male sex showed positive correlation with advanced disease recurrence which may reflect poor prognosis and higher incidence of multiple treatment failure.

Male sex was found to have significant positive correlation with size of nodal recurrence ( $p$-value $<0.05$ ) in our study, denoting more tumor burden, and more advanced disease stage at presentation.

In the eleven male patients in this study $(27.5 \%$ of all patients) median size of nodal recurrence was $2.85 \mathrm{~cm}$ with minimal nodal recurrence size $1.5 \mathrm{~cm}$ and maximum size reaching $4.5 \mathrm{~cm}$. Nine of those patients had papillary classic variant pathology $(81.8 \%)$, one with papillary follicular variant $(9 \%)$, and one with papillary columner pathology $(9 \%)$.

In the twenty nine female patients $(72.5 \%)$ the median size of nodal recurrence was $1.9 \mathrm{~cm}$, with 
minimum size of recurrence was $0.8 \mathrm{~cm}$, and maximum size $3 \mathrm{~cm}$.

On the other hand, size of operative bed recurrence didn't show significant correlation with sex. ( $p$-value 0.823$)$. In male patients $(27.5 \%)$ median size of operative bed recurrence was $1.8 \mathrm{~cm}$, with minimum size $0.7 \mathrm{~cm}$, and maximum size of recurrence $6 \mathrm{~cm}$. In the female group, $(82.5 \%)$ median size of operative bed recurrence was 2.8 months, with minimum size of recurrence $0.9 \mathrm{~cm}$, and maximum size reaching up to $14 \mathrm{~cm}$.

Time till recurrence however didn't show to have significant correlation with sex. ( $p$-value 0.402 ).

The eleven male patients $(27.5 \%)$ showed median time till recurrence 15 months with minimum time till recurrence 2 months, and maximum time of recurrence 84 months. The female patients $(82.5 \%)$ showed median time till recurrence 11 months, with maximum time till recurrence reaching 130 months, and minimum time till recurrence 2 months.

Finally sex didn't show significant correlation with number of +ve nodes removed during either primary surgery, or surgery of recurrent disease. ( $p$-value 0.725$)$.

Median number of +ve nodes removed during surgery in the eleven male patients was 4 L.N., with minimum number of +ve nodes 1 node, and maximum number of +ve removed nodes were 32 nodes. In the female patients $(82.5 \%)$, the median number of +ve nodes removed was 6 , with minimum number of +ve nodes was 0 node, and maximum number were $13+$ ve nodes.

\section{Conclusion:}

It seemed that males are more likely to present with more advanced disease stage at initial presentation, and at recurrence which mandate the need for earlier diagnose, management and strict followup in those patients to ensure that male sex will cease sometimes to constitute prognostic marker for advanced thyroid cancer.

The authors declare no conflict of interest.

\section{References}

1- MAZZAFERRI E.L.: "Papillary thyroid carcinoma: Factors influ-encing prognosis and current therapy," Seminars in Oncology, Vol. 14, No. 3, pp. 315-32, 1987.

2- MAZZAFERRI E.L. and JHIANG S.M.: "Long-term impact of initial surgical and medical therapy on papillary and follicular thyroid cancer," American Journal of Medicine, Vol. 97, No. 5, pp. 418-28, 1994.

3- SAMAAN N.A., SCHULTZ P.N., HICKEY R.C., et al.: "The results of various modalities of treatment of well differentiated thyroid carcinoma: A retrospective review of 1599 patients," The Journal of Clinical Endocrinology \& Metabolism, Vol. 75, No. 3, pp. 714-20, 1992.

4- SAMAAN N.A., MAHESHWARI Y.K., NADER S., et al.: "Impact of therapy for differentiated carcinoma of the thyroid: An analysis of 706 cases," The Journal of Clinical Endocrinology \& Metabolism, Vol. 56, No. 6, pp. $1131-8,1983$.

5- TUBIANA M., SCHLUMBERGER M., ROUGIER P., et al.: "Long-term results and prognostic factors in patients with differentiated thyroid carcinoma," Cancer, Vol. 55, No. 4, pp. 794-804, 1985.

6- SHAH J.P., LOREE T.R., DHARKER D., STRONG E.W., BEGG C. and VLAMIS V.: "Prognostic factors in differentiated carcinoma of the thyroid gland," The American Journal of Surgery, Vol. 164, No. 6, pp. 658-61, 1992.

7- SHAHA A.R.: "Implications of prognostic factors and risk groups in the management of differentiated thyroid cancer," Laryngoscope, Vol. 114, No. 3, pp. 393-402, 2004.

8- JUKKOLA A., BLOIGU R., EBELING T., SALMELA P. and BLANCO G.: "Prognostic factors in differentiated thyroid carcinomas and their implications for current staging classifications," Endocrine-Related Cancer, Vol. 11, No. 3, pp. 571-9, 2004.

9- EICHHORN W., TABLER H., LIPPOLD R., LOCHMANN M., SCHRECKENBERGER M. and BARTENSTEIN P.: "Prognostic factors determining long-term survival in well-differentiated thyroid cancer: An analysis of four hundred eighty-four patients undergoing therapy and aftercare at the same institution," Thyroid, Vol. 13, No. 10, pp. 949-58, 2003.

10-WU H.S., YOUNG M.T., ITUARTE P.H.G., et al.: "Death from thyroid cancer of follicular cell origin," Journal of the American College of Surgeons, Vol. 191, No. 6, pp. 600-6, 2000.

11- ORTIZ S., RODRÍGUEZ J.M., PARRILLA P., et al.: "Recurrentpapillary thyroid cancer: analysis of prognostic factors including the histological variant," European Journal of Surgery, Vol. 167, No. 6, pp. 406-12, 2001.

12-McCONAHEY W.M., HAY I.D., WOOLNER L.B., VANHEERDEN J.A. and TAYLOR W.F.: "Papillary thyroid cancer treated at the mayo clinic, 1946 through 1970: initial manifestations, pathologic findings, therapy, and outcome," Mayo Clinic Proceedings, Vol. 61, No. 12, pp. 978-96, 1986

13- SELLERS M., BEENKEN S., BLANKENSHIP A., et al.: "Prognostic significance of cervical lymph node metastases in differentiated thyroid cancer," The American Journal of Surgery, Vol. 164, No. 6, pp. 578-81, 1992.

14- BEENKEN S., GUILLAMONDEGUI O., SHALLENBERGER R., KNAPP C., RITTER D. and GOEPFERT H.: "Prognostic factors in patients dying of well- 
differentiated thyroid cancer," Archives of OtolaryngologyHead and Neck Surgery, Vol. 115, No. 3, pp. 326-30, 1989.

15- ANDERSEN P.E., KINSELLA J., LOREE T.R., SHAHA A.R. and SHAH J.P.: Differentiated carcinoma of the thyroid with extrathyroidal extension. Am. J. Surg., 170: 467-70, 1995.

16- CHAPLIN J.M., O'BRIEN C.J., McNEIL E.B. and HAGHIGHI K.: Aplication of prognostic scoring systems in differentiated thyroid carcinoma. Aust. N. Z. J. Surgery, 69: 625-8, 1999.

17- PALME C.E., WASEEM Z., RAZA S.N., ESKI S., WALFISH P. and FREEMAN J.L.: "Management and outcome of recurrent well-differentiated thyroid carcinoma," Archives of Otolaryngology-Head and Neck Surgery, Vol. 130, No. 7, pp. 819-24, 2004.

18- MACHENS A., HAUPTMANN S. and DRALLE H.: “ Disparities between male and female patients with thyroid cancers: Sex difference or gender divide". Clin. Endocrinol. (Oxf). Oct., 65 (4): 500-5, 2006.

19- NILUBOL N., ZHENG L. and KEBEBEW E.: "Multivariate analysis of the relationship between male sex, disease-specific survival, and features of tumor aggressiveness in thyroid cancer of follicular cell origin. Thyroid. Jun.; 23 (6): 695-702. Doi: 10.1089/Thy.2012. 0269.Epub 2013 may28, 2013.

\title{
الجنس الذكرى كعامل مؤثر فى وجود حجم آكبر للغدد اللمفاوية

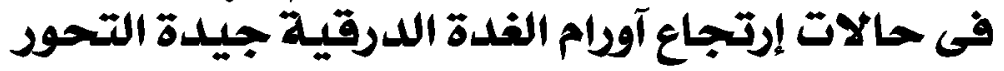

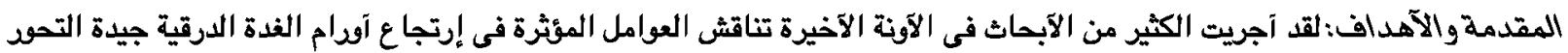

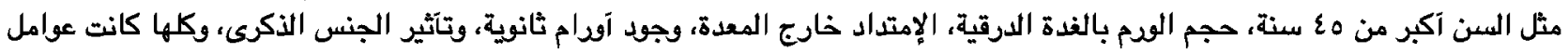

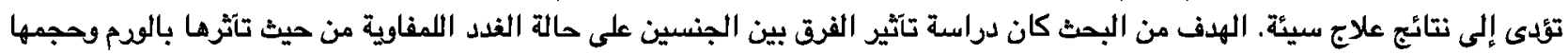

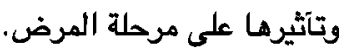

النتائج: وجد آن الذكود يكونوا آكثر تآثرا بغدد لمفاوية مصابة بالودم آكبر فى الحجم من الإناث مما يضع هؤلاء المرضى فى مرحلة آكثر تقدما للمرض.

الخلاصة: من الواضِ آن المرضى الذكى عند إكتثافهم اللمرض آق لإرتجاع القدم يكونوا في مرحلة متقدمة آكثر من الإناث مما يتطلب

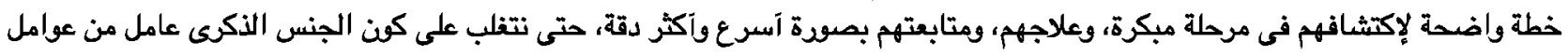

